\title{
DIGITAL LITERACY IN SPECIAL EDUCATION: A CASE STUDY OF TEACHING MUSIC TECHNOLOGY ONLINE TO A SPECIAL NEEDS LEARNER
}

\author{
Ioannis Makris \\ High School of Pedagogical and Technical Education, Greece
}

\begin{abstract}
The Covid-19 pandemic and the lockdowns enforced by many countries resulted in indispensable adjustments to the way people live and communicate. The introduction of online education in secondary and tertiary education was one such adjustment and gave rise to a new dynamic whose educational angle and potential were unknown to many teachers. Special Education teachers in particular encountered difficulties with online teaching, stemming from a number of issues common in their field: lack of uniformity special education cases present; the confusion and stress of special needs learners when faced with the teacher's physical absence; a dearth in studies on teaching Music Technology to people with mental disabilities; and the fact that Music Technology necessitates that learners already be in possession of certain digital skills. The present study aims at presenting not only its researchers' systematic recording of their teaching approach but also of the researchers' actions (March 2020 lockdown-present) regarding the teaching of Music Technology online to a learner with Down syndrome, through differentiated teaching, motivation, steady interaction, and communication. Assessment was accomplished through systematic observation of the learning process, successful completion by the special needs learner of specially designed actions, and semistructured interviews at the end of every session.
\end{abstract}

Keywords: Digital literacy, special education, music technology, online distance education.

\section{Introduction}

The social distancing measures taken and the lockdowns set in motion during the Covid-19 pandemic resulted in radical changes in the lifestyle of citizens (Macri \& Makris, 2020). Those changes impacted negatively on the social, economic, cultural, psychological, and educational level of all countries. Educational systems throughout the globe were and are still being severely tried due to the pandemic (Subramanian, Mohamed \& Khanzadah, 2020). In fact, the need for educational systems and policies worldwide to rapidly adapt to the new circumstances and especially to online teaching and learning (Sun, Tang, \& Zuo, 2020) became imperative, turning into an inescapable one-way street so as to check the spread of the pandemic and allow educators to seamlessly continue their work (Oranburg, 2020). 
Makris, 2021. Digital Literacy in Special Education: a Case Study of Teaching Music Technology Online to a Special Needs Learner

It was a process that tertiary education found easier to adapt to than secondary education, since the new challenges decreed that teaching would be conducted online. That was a teaching practice that many universities were already familiar with, due to their experience with long-distance learning programs and their implementation through best practices (Picciano, 2017). As to universities that had no prior experience with online learning, they were eventually able to integrate the new practices into their policies since, as the tertiary institutions that they were, they possessed the infrastructure and suitably trained scientific personnel to do so. It was thus that universities were able to continue with relative ease their educational functions despite the social distancing restrictions, in contrast to secondary education institutions which went through a period of severe trials and tribulations before succeeding in adapting to the new, harsher reality that arose from the pandemic and challenged teachers and learners alike.

Due to manifold and complex reasons, things are not been so clearly cut in the case of Special Education where teachers work with learners afflicted with a number of discrete mental disabilities. In other words, teachers are called on to deal with cases lacking uniformity due to the difference in the degree and type of each learner's disability (Makris \& Macri, 2019). Another issue regarding the difficulties entailed in teaching learners with mental disabilities is the psychological and emotional void disabled learners experience due to the physical absence of the teacher during an online session. If truth be told, nothing can replace the conventional way of teaching in a classroom where both teacher and learners (non-disabled and disabled alike) are physically present. Therefore, it should come as no surprise that, with the Special Education teacher physically absent during an online session, learners with disabilities experience confusion and distress. Last but not least, one more reason why Special Education teachers encounter difficulties when engaging in online teaching is that learners with mental disabilities have little or no degree of digital literacy precisely because each one's particular disability impedes their effort to handle digital learning with ease. In view of the difficulties described above, it is no wonder that there is an all-too-apparent absence of any bibliography on the triptych Special EducationMusic Technology-Online Teaching.

The goal of the present study is to present our proposal on how to promote digital literacy among learners with mental disabilities by teaching them online the particulars of Music Technology. The theoretical framework we used is anchored on Gagne's Nine Events in Instruction (Gagne, 1977); and on Anderson's Online Learning Model (Anderson, 2011). Our empirical study presents the teaching actions carried out during our online teaching sessions and recorded through systematic observation (March 2020-present). They regarded the case of Chris, a learner with Down syndrome (Trisomy 21) who was taught 
Music Technology via a Digital Audio Workstation (DAW) and, more specifically, the tools made available by the Soundation Studio online. In order to reinforce the positive psychology of the learner under observation, our teaching approach combined differentiated teaching with knowledge-building, in tandem with our effort to create motives and steadily interact as well as communicate with Chris. Evaluation was realized through the systematic observation of the teaching sessions, the successful completion by the learner of specially designed actions, and semi-structured interviews given by Chris at the end of every teaching session. Suffice it to say, that those teaching sessions, not to mention the exceptional results, have been so rewarding and significant, as to be impressively obvious to all parties involved: the teacher, the learner, and the learner's social environment. We believe, therefore, that the present study merits attention since it bridges the broad bibliographical gap that exists on the threefold issue of engaging to teach online Music Technology to Special Education learners.

Our study complied with the ethics governing cases such as Chris' case. Moreover, it met with the full approval of Chris himself as well as with the full approval of his guardians.

\section{Literature}

The challenges but also the potential that the contemporary digital environment provides, necessitate a methodical approach to digital literacy by all educational levels, including Special Education: “Digital literacy includes a large variety of complex cognitive, motor, sociological, and emotional skills, which users need in order to function effectively in digital environments" (Eshet-Alkalai, 2004, p.93) Through digital literacy, the digital skills learners will develop can easily prove of use to them, since Special Education teachers can steer those skills to motivate their learners to engage in other Special Education sectors as well. Still, studies on teaching do point out that the educational experience necessitates a combination of the teaching, cognitive, and social presence of all involved (Garrison \& Anderson \& Archer, 2010). Thus, in order to plan a teaching session, teachers can appropriately select from the element of Cognitive Presence the categories Exploration, Integration, Resolution, and Triggering Event (Garrison, Anderson, \& Archer, 2010) in order to engage their learners' interest and motivate them.

Recent studies (Makris, 2020a, b) have indicated the need for differentiated teaching in Special Education and the need for visualization (Makris, 2013; Makris 2015), especially when teaching learners with mental disabilities (Makris 2017). At this point, it is worth adding that Gardner's Theory of Multiple Intelligences (Gardner, 1983) may prove another useful tool for teachers when 
designing their planning sessions. Some key points of Gardner's theory are: every person possesses some combination stemming from eight kinds of "intelligences", with the possible addition of a ninth, the "existentialist intelligence" (Bakić-Mirić, 2010). This random grouping of developed and underdeveloped intelligences (strengths and weaknesses): (1) renders each person unique and subsequently resulting in diversity of thought; (2) we can all develop our own individual intelligences to a sufficient level through encouragement, enrichment, and suitable guidance; (3) The group of intelligences each person possesses always collaborate and interact; (4) no one intelligence can exist on its own.

Equally significant when engaging in lesson planning is taking into consideration Gagne's Nine Events of Instruction which, in essence, act as a model for systematically steering in the right direction the task of defining the goals and strategies that will result in an effective learning process (Gagne, 1977). Those nine events are: (1) Gaining attention; (2) Describing the goal to learners; (3) Stimulating retrieval of prior knowledge; (4) Presenting the particular material to be learned; (5) Providing guidance for the learning process; (6) Eliciting performance; (7) Providing reinforcement in the form of feedback; (8) Assessing performance; and (9) Enhancing retention and transfer.

Last, in terms of the present article's subject, i.e., digital literacy in Special Education through teaching music technology online, we should note the following: digital literacy, online teaching/learning, music technology, and Special Education, each have their own distinct and specific literature. Be that as it may, there is no literature that groups those fields together and addresses them as one. That realization leads us to the conclusion that there is a dearth in studies and, more specifically, empirical ones, on those fields as a group. The present study aims at addressing that gap through the systematic recording of empirical data and actions on digital literacy, online teaching, music technology, and Special Education as a group.

\section{Methodology - Description of Case}

Our case study is linked to the case described below, a learner of ours with Down syndrome (Trisomy 21). Chris' mental disability is average (IQ: 39) and suffers from slight-to-medium hearing loss. He is 34 years old. His overall degree of disability stands at $85 \%$. Chris resides with his mother and is on very good terms with his mother's family and especially his cousins. For five years, Chris was a member of the Ichochroma (Timbre) Orchestra that we had created through the D.D.A.T.A. method while working at "Ergastiri", a workshop stewarded by the Association of Parents and Guardians of Persons with Disabilities in Athens, Greece (Makris, 2020a,b). Before joining the Ichochroma Orchestra, Chris had exhibited no particular musical skills. At this point, it is worth noting that Chris 
is exceptionally sociable with a great fondness for all that is art: dance, music, painting, and theater. Along general lines, Chris likes singing but his occasional stuttering causes him problems. As a result of his stuttering, which emerges when he wishes to express himself verbally, Chris becomes frustrated and stressed. Moreover, he cannot render the pitch of a musical note correctly. Our experience leads us to believe that Chris' partial hearing loss has something to do with it: he cannot hear the pitch correctly and, as a result, he cannot reproduce it with precision. Moreover, Chris needs to be constantly monitored when it comes to rhythm because he easily becomes enthusiastic, loses focus, and finds himself off tempo while performing a musical piece. After closely observing him during the rehearsals and performances of the Ichochroma Orchestra, we came to the conclusion that Chris was best suited for santouri, a Greek string instrument, on which he was successful in developing a number of skills. As a member of that orchestra, Chris has performed at several prestigious concerts and presentations such as the Athens Concert Hall, the Ermioni International Festival, and the Ceremonies Hall at the University of Athens.

\section{Duration of Program and Sessions}

With Chris, we held one, one-hour session per week during the period May 2020-present. We made small adjustments to the program for the months of August and December in 2020: In August, we held only two sessions every fortnight, while sessions in December took place only during the first, three Sundays of the month. Overall, we carried out thirty-one sessions with Chris.

\section{Equipment}

The equipment we used was an ordinary laptop, equipped with a camera and speakers, which had broadband access to the Internet. The Digital Audio Workstation (DAW) tool we used was the Soundation Studio that provides audio samples, instruments, and effects. We selected the Soundation Studio as the platform Chris would work on, using the rationale that it is a tool that does not need to be downloaded or installed on a PC since users can access it online and create music, also directly, online. We communicated verbally with Chris, our case, via video conferencing. To that purpose, we first tried the Viber crossplatform software, next we communicated with him via Skype, Facebook Messenger but we also used the CISCO Webex video-conferencing tool. In any case, our choice to communicate through share screening (desktop sharing) was of pivotal importance since it allowed us to monitor Chris' work right on his PC. 
Makris, 2021. Digital Literacy in Special Education: a Case Study of Teaching Music Technology Online to a Special Needs Learner

\section{Stages and Analysis of Sessions}

We held thirty-one (31) video conferences sessions with Chris. The first step in every session involved his reporting to us what we had discussed and accomplished during the previous session. The second was to ask him whether he had been able to complete the homework he was assigned in-between sessions since, at every session, Chris was always given some homework to do. His homework assignments involved his experimenting with the various Soundation features and tools so as to hone his skills through practicing. Next, we would show him one or two new features of the Soundation Studio. Once he was shown the features, we would ask him to apply them on different examples to ensure that he had grasped the way the functions worked. Each session ended with our giving him an overview of the session through questions on Soundation applications. We would conclude each session by assigning him his homework for the week before our next session.

\section{Table 1 Sessions and Activities}

\begin{tabular}{|c|c|}
\hline Sessions & Activities taught per session \\
\hline 1 & $\begin{array}{l}\text { Helped Chris become autonomous in video-conferencing and turning on and off the } \\
\text { Soundation Studio - monitored practice. }\end{array}$ \\
\hline $2 \& 3$ & $\begin{array}{l}\text { Taught Chris to select and listen to samples from Soundation's sound libraries - } \\
\text { monitored practice. }\end{array}$ \\
\hline $4 \& 5$ & $\begin{array}{l}\text { Explained to Chris the concepts of beats per minutes (bpm) and tempo; trained him to } \\
\text { search through the sound library for samples that contained the same bpm and key we had } \\
\text { taught him - monitored practice. }\end{array}$ \\
\hline $6 \& 7$ & $\begin{array}{l}\text { Hands-on training of Chris to Drop \& Import audio/MIDI files from the Soundation } \\
\text { library; explained the workings of a DAW channel - monitored practice. }\end{array}$ \\
\hline 8 & Taught Chris how to use the $<$ Play $>$ and $<$ Stop $>$ commands - monitored practice \\
\hline $9 \& 10$ & $\begin{array}{l}\text { Trained Chris in using the editing commands to create, move, cut, copy or delete an } \\
\text { "event”; helped him create his first project - monitored practice. }\end{array}$ \\
\hline 11 & $\begin{array}{l}\text { Taught Chris to add an audio channel and learn about voice recordings - monitored } \\
\text { practice. }\end{array}$ \\
\hline $12 \& 13$ & $\begin{array}{l}\text { Taught Chris to handle the volume function in every sound track and the automation } \\
\text { function in the }<\text { Volume }>\text { and }<\text { Pan }>\text { commands - monitored practice. }\end{array}$ \\
\hline 14 & Taught Chris to create an instrument channel - monitored practice. \\
\hline $15 \& 16$ & Chris to use the virtual keyboard - monitored practice. \\
\hline $17 \& 18$ & $\begin{array}{l}\text { Showed Chris how to make his own sound recording using the virtual keyboard - } \\
\text { monitored practice. }\end{array}$ \\
\hline $19 \& 20$ & $\begin{array}{l}\text { Guided Chris on using MIDI-editing by using the }<\text { Edit Note }>\text { handle the }<\text { Pencil }>\text {, and } \\
\text { create his own MIDI music composition, - monitored practice. }\end{array}$ \\
\hline 21 & $\begin{array}{l}\text { Explained the basics of the Simple Synth polyphonic synthesizer, and how to use } \\
\text { Soundation's instrument channels - monitored practice. }\end{array}$ \\
\hline 22 & $\begin{array}{l}\text { Taught Chris the basics of the Mono Synth, and how to use its virtual instruments - } \\
\text { monitored practice. }\end{array}$ \\
\hline 23 & its virtual instruments work - monitored practice. \\
\hline
\end{tabular}




\begin{tabular}{|l|l|}
\hline $\mathbf{2 4}$ & $\begin{array}{l}\text { Taught Chris the basics of the VA Synth, and how to use its virtual instruments - } \\
\text { monitored practice. }\end{array}$ \\
\hline $\mathbf{2 5}$ & $\begin{array}{l}\text { Trained Chris on the use of the Wub Machine (remixer), and how to use its virtual } \\
\text { instruments - monitored practice. }\end{array}$ \\
\hline $\mathbf{2 6}$ & $\begin{array}{l}\text { Explained the basics of the GM-2 instrument sample player [synthesizer] and how to use } \\
\text { its virtual instruments - monitored practice. }\end{array}$ \\
\hline $\mathbf{2 7}$ & $\begin{array}{l}\text { Showed Chris the basics of SAM-1 Synthesizer with a capacity for sampling, and how to } \\
\text { use its virtual instruments - monitored practice. }\end{array}$ \\
\hline $\mathbf{2 8}$ & $\begin{array}{l}\text { Explained how to use or deactivate the Reverb Effect Channel - monitored practice. } \\
\text { monitored practice }\end{array}$ \\
\hline $\mathbf{2 9}$ & $\begin{array}{l}\text { Introduction to the use or deactivation of the Compressor (volume equalizer) - monitored } \\
\text { practice. }\end{array}$ \\
\hline $\mathbf{3 0}$ & $\begin{array}{l}\text { Guided Chris through the steps of exporting his project in MP3 digital audio- monitored } \\
\text { practice. }\end{array}$ \\
\hline $\mathbf{3 1}$ &
\end{tabular}

Based on the log we maintained during Chris' training period, the breakdown of the sessions, together with the breakdown of the assignments we gave Chris each session are presented analytically in Table 1 . The transition from one activity to the next would not take place unless we had made absolutely certain that Chris had fully grasped the details of the previous assignment and, more importantly, unless we were able to see that he had successfully completed the homework assignment we had given him. We should note at this point that, during all sessions, we would closely monitor and steer him in the right direction while he practiced.

Table 2 presents two screenshots from our Cisco Webex video-conferencing sessions with Chris. The first photograph (Photograph 1) shows a SAM-1 Synth where Chris practices his automation and sound design skills. The second photograph (Photograph 2) shows the MIDI screen where Chris practices his MIDI-editing skills.

\section{Table 2 Screenshots from our Cisco Webex Video-conferencing Sessions with Chris}

\begin{tabular}{|c|c|}
\hline $\begin{array}{c}\text { Photograph 1 } \\
\text { Our video conference with Chris on automation } \\
\text { and sound design using a SAM-1 Synth }\end{array}$ & $\begin{array}{c}\text { Photograph 2 } \\
\text { Our video conference with Chris on } \\
\text { MIDI Editing }\end{array}$ \\
\hline
\end{tabular}


Makris, 2021. Digital Literacy in Special Education: a Case Study of Teaching Music Technology Online to a Special Needs Learner

\section{Results}

The results of our experience stemming from teaching Chris, a special needs person, music technology online have been rewarding despite the fact that we are discussing the study of a single case. The semi-structured interviews we held with Chris also showed that the results of our work were impressive. Practically speaking, Chris improved his digital literacy and his overall skills in using the new technologies. More specifically, our thirty-one sessions with Chris helped him: (a) Start and stop on his own any videoconference, be it on Messenger, Skype or Webex; (b) open, close, export, and save audio files on a Digital Audio Workstation (DAW) which, in his case, was the Soundation Studio; (c) handle the mouse on his own by practicing Drag \& Drop, Select, Delete and, in general, all the commands he had to know to be able to audio edit on software such as a DAW; (d) use the synthesizer of his choice and make any adjustments requested of him; (e) use the Soundation Studio's Automation function and various effects (Reverb, Equalizer, and Compressor) he had been taught; (f) do basic sound mixing on his own; and (g) express himself by creating new compositions.

By means of learning how to operate and handle a DAW, not only did Chris improve his digital literacy level but he also took his self-esteem and selfknowledge to higher levels. Every time we reviewed the material taught with Chris, we all made notes of what he had learned, what we could do, and what was left to be learned. That practice significantly reinforced Chris' self-knowledge. What is more, Chris showed great improvement in a number of his cognitive functions such as his procedural memory, auditory perception, thinking process, and attention span, together with his foreign language skills since the terminology on a DAW is in English.

\section{Discussion}

Music technology on its own is a highly demanding field that necessitates in-depth knowledge on sound synthesis and digital signal processing. With the need arising from the Covid-19 pandemic to teach exclusively online, music technology becomes an even more demanding teaching subject, especially when it is addressed to individuals with mental disabilities who feel somewhat perplexed and stressed by video-conferencing and the absence of the teacher's physical presence. As Special Education teachers we were thus challenged to work in this innovative way with 34-year old Chris who was born with Down syndrome. We were amply rewarded. Today, Chris is in a position to perform tasks that neither he nor we would have thought possible six months ago.

Needless to say, our sessions with Chris are not over. However, from this point forward, our goal is to help him acquire a firmer grasp of the concepts and 
skills he was taught, and monitor him while he produces on his own a complete musical project in CD form. For the thirty-one sessions with Chris we anchored ourselves in our prior Special Education experience and followed Gagne's Nine Events (Gagne, 1977) for the design of the educational material destined for Chris. As a result, we were able to produce a protocol (Table 1 ). That protocol may very well be the first applied teaching guide for those who wish to teach music technology online to persons with mental disabilities. We hope that, in future, our protocol may provide the foundation for the development of the relevant curriculum.

\section{References}

Anderson, T. (2011). Online Learning Model. The theory and practice of online learning. (2nd Edition). Edmonton, AB: AU Press.

Bakić-Mirić, N. (2010). Implementation of multiple intelligences theory in the English language course syllabus at the University of Nis Medical School. Srp Arh Celok Lek., 138(1-2), 105-110.

Eshet-Alkalai, Y. (2004). Digital Literacy: A Conceptual Framework for Survival Skills in the Digital Era, Journal of Educational Multimedia and Hypermedia, v13, n1, 93-106.

Gardner, H. (1983). Frames of Mind: The Theory of Multiple Intelligences. NYC: Basic Books. Gagne, R.M. (1977). The conditions of learning. New York: Holt, Rinehart \& Winston.

Garrison, D.R., Anderson, T., \& Archer, W. (2010). The first decade of the community of inquiry framework: A retrospective, The Internet and Higher Education, Volume 13, Issues 1-2, 5-9.

Macri, D, Makris, I. (2020). Mental Health and the Covid-19 Lockdown: International Quantitative Study. International Journal of Psychiatry, 3(4), 1-9.

Makris, I. (2020a). The Differentiated Didactic Approach to Teaching the Arts (D.D.A.T.A.) in Special Education and Positive Psychology. Psychology, 11, 551-562.

Makris, I. (2020b). A Differentiated Didactic Approach to Teaching the Arts (D.D.A.T.A.) for the Purposes of Special Education and Training. International Scientific conference Society. Integration. Education. Proceedings, Rezekne, Rezekne Tehnologiju Akademija.

Makris, I. (2017). Visualisation and Verbalization in the Use of Special Music Education. In International Scientific conference Society. Integration. Education. Proceedings, Rezekne, Rezekne Tehnologiju Akademija.

Makris, I. (2015). Creating a Traditional Orchestra for the Needs of Special Education. In International Scientific conference Society. Integration. Education. Proceedings, Rezekne: Rezekne Tehnologiju Akademija.

Makris, I. (2013). The role of philately in Musical education an cross-cultural interaction. In International Scientific conference Society. Integration. Education. Proceedings, Rezekne, Rezekne Tehnologiju Akademija.

Makris, I., Macri, D. (2019). Special needs children in school (inclusion): Quantitative study no students attitudes. International Scientific conference Society. Integration. Education. Proceedings. Rezekne: Rezekne Tehnologiju Akademija.

Oranburg, S. (2020). Distance Education in the Time of Coronavirus: Quick and Easy Strategies for Professors. Legal Studies Research Paper Series. Duquesne University School of Law Research Paper No. 2020-02. 
Makris, 2021. Digital Literacy in Special Education: a Case Study of Teaching Music Technology Online to a Special Needs Learner

Picciano, A. G. (2017). Theories and frameworks for online education: Seeking an integrated model. Online Learning, 21(3), 166-190. doi: 10.24059/olj.v21i3.1225.

Subramanian, S, Mohamed, S, Khanzadah, T. (2020). The Coronavirus' Impact on Education School Students’ Perspective. Int J Nutr Pharmacol Neurol Dis, 10, 166-7.

Sun, L., Tang, Y. \& Zuo, W. (2020). Coronavirus pushes education online. Nat. Mater. 19, 687. https://doi.org/10.1038/s41563-020-0678-8. 